\section{ER-016 CLINICAL TRIALS: THERAPEUTIC OPPORTUNITIES, ECONOMIC IMPACT AND SAVINGS FOR THE NATIONAL HEALTH SYSTEM}

${ }^{1} \mathrm{SL}$ Borchetto*, 'B Taddei, 'F Beretta, 'D Ferrante, ${ }^{2} \mathrm{~F}$ Marchesi, 'S Nozza, ${ }^{1} \mathrm{M}$ Daminelli, ${ }^{1} \mathrm{~F}$ Gregis, ${ }^{1} \mathrm{~V}$ Gatti, ${ }^{1} \mathrm{M}$ Sottocorno. ${ }^{1}$ Asst Papa Giovanni xxiii, UOC Farmacia, Bergamo, Italy; ${ }^{2}$ Asst Papa Giovanni xxiii, UOC Oncologia, Bergamo, Italy

\subsection{6/ejhpharm-2019-eahpconf.613}

Background AIFA has certified an increase in the number of nationally authorised trials of the European total $(17 \%$ in 2015, 20\% in 2016): research has become an integral part of clinical activity, as well as essential for the Italian health and economic system. ${ }^{1}$

Purpose To describe the activities that a dedicated clinical trial pharmacist carries out in the pharmacy according to Good Clinical Practice: qualitative and quantitative control, traceability, preservation, accountability and preparation of the drugs.

Material and methods In order to implement the traceability system and to ensure an easier drug accountability, a database that collects all the main information related to the shipments of incoming experimental samples was created: protocol name and EudraCT, principal investigator and destination department, qualitative and quantitative description of the drugs, ID shipment, arrival and check time, transport and storage temperature. The analysed data was collected from October 2017 to October 2018: the clinical trials managed by the oncology and haematology departments had been assigned an economic value (ex-factory price). ${ }^{2}$

Results One-thousand two-hundred and forty-nine shipments had been registered in the pharmacy, 771 of which were at controlled temperature: five times the datalogger was alarmed and the content was kept in quarantine until new directives were issued by the clinical research associate: in none of the cases was the use of the drug prevented after the verifications of competence.

$38.35 \%$ of the total shipments were addressed to the Unità Farmaci Antiblastici for preparation: the shipments of experimental samples dedicated to oncological trials were 522, while 382 were haematological ones.

The economic value attributed to the drugs was around $€ 9,800,000$ for oncological drugs and $€ 10,400,000$ for haematological ones. The new molecules (without market price) being tested are 16 for oncology and 22 for haematology.

Conclusion Onco-haematological drugs are one of the most important items of hospital pharmaceutical expenditure and an important investment by companies. Not all trials will lead to the expected result, however, they can be considered both a new therapeutic opportunity for the patient and a source of savings for the National Health System. However, whether this benefit can be confirmed, even in post-marketing, needs to be verified.

\section{REFERENCES AND/OR ACKNOWLEDGEMENTS}

1. http://www.aifa.gov.it/sites/default/files/Rapporto-OsSC_16-2017.pdf

2. https://www.codifa.it/

No conflict of interest.

\section{ER-017 ABSTRACT WITHDRAWN}

\section{ER-018 DEVELOPMENT AND PERFORMANCE EVALUATION OF THE MEDICINES OPTIMISATION ASSESSMENT TOOL: A PROGNOSTIC MODEL TO TARGET HOSPITAL PHARMACISTS' INPUT TO PREVENT MEDICATION- RELATED PROBLEMS}

${ }^{1} \mathrm{C}$ Geeson*, ${ }^{2} \mathrm{~L}$ Wei, ${ }^{2} \mathrm{BD}$ Franklin. 'Luton and Dunstable University Hospital, Pharmacy, Luton, UKi ${ }^{2} U C L$, School of Pharmacy, London, UK

\subsection{6/ejhpharm-2019-eahpconf.615}

This poster was presented at the EAHP Congress, March 2729, and is accepted for publication in the International Journal of Pharmacy Practice.

\section{ER-019 INTRODUCING YOUNG HOSPITAL PHARMACISTS TO SCIENTIFIC RESEARCH: AN EDUCATIONAL PROJECT SUPPORTED BY A NATIONAL SOCIETY FOR CLINICAL PHARMACY}

'D Mengato*, ${ }^{2} \mathrm{M}$ Chiumente. 'Bolzano General Hospital, Hospital Pharmacy, Bolzano, Italy; ${ }^{2}$ Italian Society for Clinical Pharmacy and Therapeutics, Scientific Coordination, Milano, Italy

10.1136/ejhpharm-2019-eahpconf.616 